\section{Researchers fail to dig out enough avalanche data}

Pascal Haegeli and coauthors' interpretation of their avalanche research findings is unjustified. ${ }^{1}$ The authors cannot show an association between survival times and cause of death because cause of death is not reported in the Swiss sample. An association to snow density can't be shown because it was not measured. The data show that the victims in both cohorts differed in many aspects and much potentially relevant information seems not to have been available to the authors. Because of this lack of data the authors' rather causal conclusions are not sufficiently supported. Apart from the missing data on snow and causes of death much more information on covariates would be necessary to address confounding in a convincing way.

\section{Georg Roggla MD}

Landesklinikum Thermenregion, Department of Internal Medicine, Neunkirchen, Austria

\section{Reference}

1. Haegeli P, Falk M, Brugger H, et al. Comparison of avalanche survival patterns in Canada and Switzerland. CMAJ 2011;183:789-95.

CMAJ 2011. DOI:10.1503/cmaj.111-2043

While we thank Dr. Röggla for communicating his perspective on our study, we would like to take this opportunity to clarify the methodology of our analysis and the relevance of our conclusions. ${ }^{1}$ The direct comparison between the Canadian and Swiss and datasets was used to illustrate that the shape of the avalanche survival curve is not universal, but rather strongly affected by local characteristics. The diverse character and limited amount of background information on the two cohorts, however, did not allow a more detailed comparison of potential underlying reasons. Instead, we performed comparisons among subpopulations of the Canadian dataset where more detailed records were available and the subgroups were less heterogeneous. These comparisons revealed that trauma primarily affects the survival probability at the early stages of burial and that more maritime snow climates were associated with an earlier onset of asphyxia. Debris density is strongly related to climate, i.e. snowfall amounts and air temperature, and could therefore be a plausible cause for this observation (as demonstrated in previous investigations), but we did not claim to demonstrate a direct association as density information was not available.

Limitations in avalanche accident records currently prevent us from examining the contributing factors to avalanche survival in more detail. Better information on the condition of avalanche victims at extrication, resuscitation measures, injuries of survivors, and environmental conditions are crucial for improving our understanding. It is our hope that our article will provide the necessary impetus for improved data collection and more research in this direction.

\section{Pascal Haegeli PhD}

Avalanche Consulting, Vancouver, BC

\section{Reference}

1. Haegeli P, Falk M, Brugger H, et al. Comparison of avalanche survival patterns in Canada and Switzerland. CMAJ 2011;183:789-95.

CMAJ 2011. DOI:10.1503/cmaj.111-2050

\section{Health organizations and the food industry}

The Canadian Nutrition Society agrees in part with $C M A J$ 's editorial on how partnerships between health organizations and the food industry risk derailing public health nutrition. ${ }^{1}$ The editorial's cautionary advice to health organizations on sponsorships and possible indirect influence on health promotion policies is wise. The medical community is now addressing pharma funding of continuing medical education. ${ }^{2}$ Little is gained, however, by vilifying the entire food industry, which has invested in nutrition research and strategies to effect changes in the food supply.

The agri-food industry has been doing considerable work to bridge the gap between food and health. ${ }^{3}$ The same cannot be said of the health care sector. If strides are to be made, the health care community must work with the food industry, not against it.

\section{Leah Gramlich MD}

President, Canadian Nutrition Society and Director, Nutrition Support, Division of Gastroenterology, Department of Medicine, University of Alberta, Edmonton, Alta.

\section{References}

1. Freedhoff Y, Hébert PC. Partnerships between health organizations and the food industry risk derailing public health nutrition. CMAJ 2011;183:291-2

2. Morris L, Taitsman JK. The agenda for continuing medical education - limiting industry's influence. N Engl J Med 2009;361:2478-82.

3. Agri-food destination report. Ottawa (ON): Canadian Agri-food Policy Institute; 2011. Available: www.capi-icpa.ca

CMAJ 2011. DOI:10.1503/cmaj.111-2048

Having just read the letter from Leah Gramlich on behalf of The Canadian Nutrition Society, I felt compelled to comment.

Calling into question how the health care sector defines the role of nutrition in the health of Canadians adds to the debate. When it comes to "everyday" food marketed and sold in Canada, I have yet to see any results of the "considerable work" that the agri-food industry has been doing. I do see increasing rates of obesity and diabetes and more examples of conflicts of interest.

I would feel much more comfortable if groups advocating for improvements in our public health remained at arm's length from the agri-food industry.

\section{Gavin D. Arthur \\ Courtenay, BC}

CMAJ 2011. DOI:10.1503/cmaj.111-2049

Some letters have been abbreviated for print. See www.cmaj.ca for full versions. 